\title{
Malignant Superior Vena Cava Neoplasm
}

National Cancer Institute

\section{Source}

National Cancer Institute. Malignant Superior Vena Cava Neoplasm. NCI Thesaurus.

Code C5379.

A malignant neoplasm involving the superior vena cava. 